\title{
Efeito fungitóxico do óleo essencial de aroeira da praia (Schinus terebinthifolius RADDI) sobre Colletotrichum gloeosporioides
}

\author{
OLIVEIRA JUNIOR, L.F.G. ${ }^{* *}$; SANTOS, R.B.2; REIS, F.O.2; MATSUMOTO, S.T.2; BISPO, W.M.S..; MACHADO, \\ L.P.'; OLIVEIRA,L.F.M. ${ }^{1}$ \\ ${ }^{1}$ Universidade Federal De Sergipe/Departamento de Engenharia Agronomica, Avenida Marechal Rondon, S/N, \\ CEP: 49100-000, São Cristóvão-Brasil *Ifg.ufs@gmail.com; '2Universidade Federal Do Espírito Santo/UFES, \\ Avenida Fernando Ferrari 514, CEP: 29075-910, Vitória-Brasil
}

\begin{abstract}
RESUMO: Neste trabalho foi avaliado o efeito do óleo essencial do fruto de Schinus terebinthifolius sobre o crescimento micelial do fungo Colletotrichum gloeosporioides in vitro, e no desenvolvimento da antracnose no período de pós-colheita em mamões. As diferentes concentrações de óleo foram diluídas em Tween 80 a $8 \%$. No experimento in vitro foram preparados meios de cultura BDA nas concentrações de 0,05; 0,10;0,25 e 0,50\% do óleo essencial. $\mathrm{O}$ controle negativo foi realizado apenas com meio BDA e o controle solvente com meio BDA e Tween 80 a 8\%. A inibição do crescimento do fungo foi diretamente proporcional à quantidade do óleo e a maior inibição encontrada foi de $79,07 \%$ na concentração de óleo de $0,50 \%$. No experimento in vivo os frutos do mamoeiro foram inoculados com o fungo em quatro tratamentos: com biofilme; com biofilme mais $0,50 \%$ do óleo; com fungicida Prochloraz e frutos controle. Embora o tratamento com óleo tenha sido eficiente contra o fungo, não foi indicado comercialmente, pois apresentou valores elevados de perda de massa fresca, de firmeza, e também sintomas de fitotoxidade. O óleo tem propriedade antifúngica contra C. gloeosporioides in vitro e in vivo, contudo, não é recomendado para o mamão em função da fitotoxidez
\end{abstract}

Palavras-chave: Carica papaya, Colletotrichum gloeosporioides, Schinus terebinthifolius, controle alternativo.

\begin{abstract}
Fungitoxic effect of essential oil from aroeira (Schinus terebinthifolius RADDI) on Colletotrichum gloeosporioides. This study evaluated the effect of essential oil from Schinus terebinthifolius fruit on the mycelial growth of the fungus Colletotrichum gloeosporioides in vitro and on the anthracnose development during the postharvest period of papaya fruits. The different oil concentrations were diluted in $8 \%$ Tween 80 . For the in vitro experiment, PDA culture media were prepared at the concentrations of $0.05,0.10,0.25$ and $0.50 \%$ essential oil. Negative control was prepared with PDA medium alone, while solvent control was prepared with PDA medium and $8 \%$ Tween 80 . Fungal growth inhibition was directly proportional to the oil amount and the greatest inhibition was $79.07 \%$ at $0.50 \%$ oil concentration. For the in vivo experiment, papaya fruits were inoculated with the fungus in four treatments: with biofilm, with biofilm plus $0.50 \%$ oil, with the fungicide Prochloraz and control fruits. Although treatment with oil was efficient against the fungus, it was not commercially recommended since it presented high values of loss of fresh mass and firmness, as well as phytotoxicity symptoms. The oil has antifungal property against $C$. gloeosporioides both in vitro and in vivo; however, it is not recommended for papaya fruits due to its phytotoxicity.
\end{abstract}

Key words: Carica papaya, Colletotrichum gloeosporioides, Schinus terebinthifolius, alternative control

\section{INTRODUÇÃO}

A Aroeira (Schinus terebinthifolius) é uma árvore grande, de casca fina e escamosa. Possui folhas compostas por folíolos lanceolados e pontiagudos, numerosas flores, dispostas em pedículos, pequenas e brancas ou amarelo esverdeadas. O fruto é drupa vermelha e lustrosa, cujo cheiro se assemelha ao da pimenta. É originária do Peru, sendo também encontrada na Europa, Ásia e outras regiões da América. No Brasil, tem distribuição em todo território, sendo catalogadas 
oito espécies diferentes (Lisboa-Neto et al., 1998).

Schinus terebinthifolius é uma planta que tem os frutos utilizados como condimento alimentar, tanto no mercado nacional quanto internacional (Lenzi \& Orth, 2004). O fruto possui de 5,50 a 8,41\% de óleo essencial. Este óleo apresenta composição química predominante de monoterpenos $(85,1 \%)$, sendo os mais abundantes $\delta$-3-careno $(30,37 \%)$, limoneno $(17,44 \%), \alpha$-felandreno (12,60\%), $\alpha$-pineno $(12,59 \%)$, mirceno $(5,82 \%)$ e o-cimeno $(3,46 \%)$, seguido pelos sesquiterpenos (5,34\%) trans-cariofileno, $Y$-muuruleno, $E, E$ - $\alpha$-farneseno, $\delta$-cadineno e epi- $\alpha$ cadinol (Cole, 2008). Esta espécie possui crescente uso farmacológico; é considerada pela medicina popular como adstringente, anti-diarréica, antiinflamatória, depurativa, diurética e febrífuga (Paiva \& Aloufa, 2009). A ação antifúngica de extratos de folhas de $S$. terebinthifolius é discutida para várias espécies, como Candida albicans, Cryptococcus neoformans, Candida krusei, Candida glabrata e Sporothrix schenckii (Braga et al., 2007; Johann et al., 2007).

A pesquisa fitopatológica visando o controle da população de fungos e outros microrganismos, principalmente aqueles que provocam danos à agricultura, tem tido um considerável implemento nos últimos anos através do emprego de óleos, bálsamos e extratos vegetais (Bastos,1997; David et al., 2006).

O controle de fitopatógenos tem sido feito por meio de agentes químicos sintéticos, mas o uso vem sendo restringido devido às possíveis ações carcinogênicas e teratogênicas, à alta toxidade e aos efeitos colaterais em humanos, além de originar poluição ambiental e requerer longo período de tempo para a completa degradação (Feng \& Zheng, 2007).

Segundo Feng \& Zheng (2007) o uso de óleos essenciais é promissor para o desenvolvimento de agentes antifúngicos seguros por poderem apresentar ações antimicrobianas e antifúngicas, serem relativamente seguros e largamente aceitos pelos consumidores. Por isso, diversos estudos sugerem a utilização de óleos essenciais que possuem propriedades antifúngicas na pós-colheita de frutos (Regnier et al., 2008; Sharma \& Tripathi, 2008; Feng et al., 2008).

Dessa forma, o presente trabalho teve por objetivo investigar, in vitro e in vivo, a atividade antifúngica do óleo essencial de Schinus terebinthifolius frente ao patógeno Colletotrichum gloeosporioides.

\section{MATERIAL E MÉTODO}

\section{Meio de cultivo}

O meio de cultivo utilizado, BDA (Batata Dextrose Ágar), foi preparado conforme o seguinte procedimento: Duzentos gramas de batatas foram fervidas no forno de microondas por 3 minutos com $400 \mathrm{~mL}$ de água. Ao filtrado formado após três minutos de resfriamento a temperatura ambiente foi acrescentado $600 \mathrm{~mL}$ de água destilada, 18 gramas de sacarose e 20 gramas de ágar. 0 meio de cultivo e todas as vidrarias empregadas foram devidamente autoclavadas.

\section{Isolamento do fungo}

O fungo, Colletotrichum gloeosporioides, foi isolado de culturas já pré-existentes do laboratório de Fitopatologia da INCAPER (Instituto Capixaba de Pesquisa, Assistência Técnica e Extensão Rural), Linhares Espírito Santo.

\section{Obtenção do óleo de Schinus terebinthifolius}

Frutos maduros de Schinus terebinthifolius Raddi foram colhidos no Campus da Universidade Federal do Espírito Santo (UFES), localizado em Goiabeiras, Vitória, Espírito Santo, de árvores localizadas próximas ao prédio da Secretaria do Centro de Ciências Exatas (CCE). A identificação botânica foi realizada pela professora Solange Zanotti Schneider do Laboratório de Botânica. As exsicatas das plantas representando as coletas encontram-se arquivadas no Herbário da instituição, sob o registro VIES 14711.

Os frutos foram submetidos à secagem em ambiente aberto, durante uma semana, à sombra, para que não houvesse perda dos componentes voláteis. A secagem diminui a velocidade de deterioração do material por meio da redução do teor de umidade, atuando na ação das enzimas pela desidratação, permitindo a conservação das plantas por mais tempo. Com a eliminação da água, aumenta-se o percentual de princípios ativos em relação à massa seca (Silva \& Casali, 2000).

\section{Extração do Óleo Essencial}

O óleo essencial dos frutos de Schinus terebinthifolius Raddi foi extraído pelo método de hidrodestilação de acordo com o método empregado pela AOAC (1992). O processo consiste essencialmente em volatilizar o óleo essencial com uma corrente de vapor de água (Waterman, 1993). Sendo utilizado o aparelho de Clevenger modificado (Wasicky \& Akisue, 1969), acoplado a balão de fundo redondo de $3000 \mathrm{~mL}$. A utilização do aparelho de Clevenger permite a separação do óleo e da água, além do resfriamento do óleo, evitando possíveis decomposições do mesmo.

Os frutos de Schinus terebinthifolius (200 g), descascados e triturados em liquidificador até atingirem granulometria uniforme, e $1500 \mathrm{~mL}$ de água deionizada, foram colocados no balão e levados para a manta aquecedora. O tempo de extração foi de 6 horas contadas a partir da ebulição da amostra. O hidrolato

Rev. Bras. PI. Med., Botucatu, v.15, n.1, p.150-157, 2013. 
obtido foi particionado com três porções de $30 \mathrm{~mL}$ de diclorometano em funil de separação, e seco com sulfato de sódio anidro, sendo em seguida filtrado para a separação do sulfato e levado ao rotaevaporador (Büchi) a $30^{\circ} \mathrm{C}$ e pressão reduzida $(40 \mathrm{mmHg})$ para remoção do diclorometano. Após a evaporação do solvente, o óleo essencial obtido foi pesado e armazenado em frasco âmbar sob resfriamento.

\section{Rendimento}

O rendimento do processo extrativo foi determinado pela relação massa/massa (conforme a fórmula abaixo). As massas dos óleos essenciais foram determinadas em balança semi-analítica e seus valores comparados às respectivas massas de frutos de Schinus terebinthifolius utilizadas.

\section{$\%$ de óleo essencial $=$ massa de óleo essencial obtido $(\mathrm{g}) \times 100$ \\ massa de frutos secos $(\mathrm{g})$}

Os óleos essenciais obtidos apresentaram odor forte, sabor pungente e coloração amareloclara. A porcentagem de óleo essencial extraído dos frutos de Schinus terebinthifolius Raddi variou de $5,50 \%(p / p)$ a $8,41 \%(p / p)$.

\section{Determinação da Composição Química do Óleo Essencial de Sementes de Aroeira da Praia}

A determinação da composição química dos óleos de aroeira da praia foi realizada utilizando-se um cromatógrafo gasoso da marca Varian, modelo 4000, acoplado a um espectrofotômetro de massa (MS) e equipado com uma coluna capilar CP-WAX52CB, com $30 \mathrm{~m}$ de comprimento, diâmetro de $0,25 \mathrm{~mm}$ e espessura do filme de $0,25 \mu \mathrm{m}$, sendo o hélio 5.0 o gás carreador. A identificação das substâncias foi efetuada através da comparação dos índices de retenção de Kovats obtidos experimentalmente com os valores tabelados Adams (2001). Também foi utilizada a data base da biblioteca do equipamento (NIST - Natural Institute of Standards \& Tecnology, USA) que permite a comparação dos dados dos espectros com aqueles constantes da biblioteca. Para o cálculo do índice de retenção de Kovats, uma mistura de padrões de alcanos lineares (C9 a C24) foi injetada no aparelho $(0,5 \mu \mathrm{L})$ nas mesmas condições cromatográficas anteriormente citadas.

\section{Ensaios microbiológicos}

Os ensaios microbiológicos foram realizados em placas de Petri $(60 \times 15 \mathrm{~mm})$, contendo meio BDA. As diferentes concentrações de óleo do fruto de $S$. terebinthifolius testadas foram diluídas em BDA e Tween 80 a $8 \%$ (surfactante). Foram utilizadas as concentrações de 0,$05 ; 0,10 ; 0,25$ e $0,50 \%$ do óleo. Foram feitos controle negativo apenas com BDA e um controle solvente com BDA e Tween 80 a $8 \%$, totalizando 6 tratamentos.

Cada tratamento foi feito em triplicata, perfazendo dezoito placas de Petri. Após a solidificação do meio, discos de papel filtro de $5 \mathrm{~mm}$ de diâmetro foram transferidos para o centro das placas e foi adicionado a estes $3 \mu \mathrm{L}$ de suspensão de esporos de C. gloeosporioides na concentração de $1,5 \times 10^{6}$ conídios $\mathrm{mL}^{-1}$. Nas placas de Petri foram feitos dois eixos perpendiculares com o auxílio de caneta de retroprojetor, para facilitar a medição de crescimento micelial. As placas de Petri inoculadas foram, então, incubadas em câmara de crescimento tipo BOD (Biological Oxygen Demand) a temperatura de $281^{\circ} \mathrm{C}$.

Foram realizadas medidas do diâmetro da colônia, sobre os eixos perpendiculares, com auxílio de paquímetro digital de marca Digimess. As medidas foram realizadas nos dias 2, 4, 6 e 8 após a inoculação.

O cálculo do índice de velocidade de crescimento micelial (IVCM), expresso em cmdia-1 foi realizado conforme proposto por Gomes, (2008), por meio da seguinte fórmula:

$\operatorname{IVCM}=\Sigma(\mathrm{D}-\mathrm{Da}) / \mathrm{N}$

Onde,

D: Diâmetro médio atual

Da: Diâmetro médio anterior

$\mathrm{N}$ : número de dias após a inoculação

Os dados de IVCM foram submetidos à análise estatística por meio da Análise de Variância ANOVA e posteriormente teste de comparação de médias Tukey $(p<0,05)$, por meio do programa Assistat 7.5 beta.

\section{Controle do fungo Colletotrichum gloeosporioides in vivo}

Os frutos de mamão do grupo Solo, cultivar Golden utilizados no ensaio foram colhidos no estádio de maturação 1, e lavados em solução de hipoclorito de cálcio $200 \mathrm{mgL}^{-1}$ e duas vezes em água. Após secagem em bandejas de plástico, foi efetuado ferimento por um conjunto de agulhas entomológicas em três pontos da superfície do fruto. Em cada orifício foram colocados 3 ì de suspensão de esporos na concentração de $1,3 \times 10^{6}$ conídiosmL $^{-1}$ e, em seguida, os frutos foram submetidos aos tratamentos de frutos controle, sem inoculação de patogenos (C); frutos envolvidos com biofilme de 
amido (B); frutos envolvidos com biofilme de amido e $8 \%$ de Tween 80 com $0,5 \%$ de óleo essencial de aroeira (O); e frutos tratados com fungicida Prochloraz a $0,025 \%$ imersos por 3 minutos $(F)$. Para cada tratamento foram empregados 3 frutos, sendo que cada fruto constituiu uma repetição. Após as inoculações, os frutos foram incubados à temperatura de $25^{\circ} \mathrm{C}$ e UR em torno de $80-85 \%$. As avaliações foram efetuadas aos oito dias após as inoculações, mediante: a) perda de massa fresca (PMF), obtida pela diferença entre o peso inicial e o final expresso em porcentagem; $\mathbf{b}$ ) firmeza da região mediana, medida pela resistência ao penetrômetro Effegi modelo FT 011 (ponta de $8 \mathrm{~mm}$ ), expressandose os resultados em $\mathrm{kgF}$; c) sólidos solúveis (SS), avaliados através da leitura refratométrica direta, com refratômetro modelo RT-30ATC (Instrutherm Instrumentos de Medição LTDA), expressos em -BRIX; d) acidez titulável (AT), avaliada através de titulometria de neutralização $(\mathrm{NaOH} 0,2 \mathrm{~N}) \mathrm{com}$ ponto de viragem no $\mathrm{pH}=8,1$, e resultado expresso em mg de ácido cítrico $100 \mathrm{~mL}^{-1}$ de suco (AOAC, 1992); e) $\mathrm{pH}$, por potenciometria (AOAC, 1992); e f) determinação da incidência (número de frutos infetados em cada tratamento).

O delineamento experimental foi inteiramente casualizado. A análise estatística foi realizada por meio do programa Assistat 7.5 beta, sendo os dados submetidos à análise de variância (ANOVA) e as médias comparadas pelo teste $T$ $(p<0,01$ e $p<0,05)$.

\section{RESULTADO E DISCUSSÃO}

Determinação da Composição Química do
Óleo Essencial de Sementes de Aroeira da Praia
A partir das informações contidas na tabela
1, observou-se que foram identificados 16 compostos
majoritários, totalizando mais de $91 \%$ da composição
química do óleo essencial de aroeira. Após 6 h de
destilação o óleo apresentou os compostos $\rho$-menth-
1-en-9-ol, o canfeno, o germacreno-D, o hedicariol,
o a-gurjuneno, o a-eudesmol e o $\beta$-eudesmol como
compostos majoritários.
O perfil fitoquímico do óleo essencial obtido neste trabalho foi diferente do apresentado por outros autores (Barbosa et al., 2007; Santos et al., 2007), onde se verificou, por exemplo, a presença de $\alpha$-felandreno, $\beta$-felandreno, elemol, $\alpha$-cadiol, sabineno, $\delta$-3-careno e sylvestreno, enquanto que neste trabalho não foram observados esses compostos, evidenciando que as características genéticas da planta e os fatores abióticos interferem significativamente na composição química do óleo essencial de aroeira, também observado por (Ibraim et al., 2001), que relataram a grande variação
TABELA 1. Compostos voláteis identificados no óleo essencial extraído de sementes de aroeira da praia.

\begin{tabular}{|c|c|c|}
\hline & & $\begin{array}{c}\text { Tempo de } \\
\text { Destilação }\end{array}$ \\
\hline Composto & T. $\mathbf{R}$. & $\% 6,0 \mathrm{~h}$ \\
\hline p-Mmenth-1-en-9-ol & 4.393 & 8,321 \\
\hline$\beta$-pineno & 4.527 & 1,429 \\
\hline a-thujeno & 4.586 & 1,302 \\
\hline canfeno & 5.210 & 4,785 \\
\hline$\alpha-$ fencheno & 5.401 & 8,463 \\
\hline acetato de terpinen-4-ol & 7.131 & 0,619 \\
\hline acetato de bornyl & 16.646 & 1,797 \\
\hline caryofileno & 17.218 & 2,190 \\
\hline terpinen-4-ol & 17.540 & 1,307 \\
\hline a-terpineol & 20.970 & 1,380 \\
\hline germacreno - D & 21.193 & 7,912 \\
\hline ס-cadineno & 23.028 & 1,094 \\
\hline hedycaryol & 33.754 & 18,734 \\
\hline a-gurjuneno & 36.320 & 12,033 \\
\hline a-eudesmol & 37.825 & 9,177 \\
\hline$\beta$-eudesmol & 38.018 & 11,151 \\
\hline Outros & & 8,609 \\
\hline
\end{tabular}

T.R.: Tempo de Retenção em minutos.

da composição química dos óleos essenciais de plantas ligadas diretamente a fatores genéticos $\mathrm{e}$ ambientais.

\section{Controle do fungo Colletotrichum gloeosporioides in vitro}

Foram observadas diferenças significativas entre o IVCM nos diferentes tratamentos. Os tratamentos controles negativo e solvente não diferiram estatisticamente e apresentaram os maiores índices de velocidade de crescimento micelial (Tabela 2). Por outro lado, as concentrações de 0,$05 ; 0,10$ e de $0,25 \%$ apresentaram IVCM intermediários. A concentração de $0,50 \%$ foi a que apresentou o crescimento mais lento, com média de $1,04 \mathrm{cmdia}^{-1}$, enquanto o controle negativo cresceu a 4,96 $\mathrm{cmdia}^{-1}$ (Tabela 2).

$\mathrm{Na}$ Tabela 2, encontra-se, também, a capacidade das diferentes concentrações do óleo essencial em inibir o crescimento do fungo em porcentagem. Constatou-se que na concentração correspondente a $0,50 \%$ houve maior inibição $(79,07 \%)$ do crescimento micelial.

Desta forma, o óleo essencial de $S$. terebinthifolius apresentou propriedade antifúngica contra o fungo $C$. gloeosporioides, a qual aumentou, significativamente, com o aumento da concentração 
TABELA 2. Valores médios e erro padrão do índice de velocidade de crescimento micelial (IVCM) $(\mathrm{cm}$ dia $^{-1}$ ) e valores médios da capacidade de inibição do IVCM (\%) de Colletotrichum gloeosporioides em BDA nas diferentes concentrações do óleo de Schinus terebinthifolius e nos controles.

\begin{tabular}{ccc}
\hline & IVCM (cm dia-1) & Inibição do IVCM (\%) \\
\hline CN & $4,96 \pm 0,17 \mathrm{a}$ & 0,00 \\
CS & $5,36 \pm 0,03 \mathrm{a}$ & 0,00 \\
$0,05 \%$ & $4,57 \pm 0,11 \mathrm{ab}$ & 7,88 \\
$0,10 \%$ & $3,78 \pm 0,44 \mathrm{bc}$ & 23,80 \\
$0,25 \%$ & $2,81 \pm 0,22 \mathrm{c}$ & 43,33 \\
$0,50 \%$ & $1,04 \pm 0,15 \mathrm{~d}$ & 79,07 \\
\hline
\end{tabular}

Médias seguidas da mesma letra não diferem estatisticamente, pelo teste de Tukey, a $5 \%$ de probabilidade.

$\mathrm{CN}$ - Controle negativo BDA e CS - Controle solvente BDA + Tween 80 a 8\%. 0,05\%, 0,10\%, 0,25\% e 0,50\% - Concentrações de óleo essencial de Schinus terebinthifolius no meio BDA

do óleo (Tabela 2). Com concentrações do óleo essencial acima das testadas provavelmente 0 crescimento micelial seria completamente inibido, entretanto, o aumento na concentração do óleo aumentaria os custos de produção do fungicida natural inviabilizando a utilização em escala comercial. Desta forma, a concentração de 0,50\% do óleo de Schinus terebinthifolia Raddi pode ser indicada para o controle do fungo por apresentar inibição do crescimento micelial de Colletotrichum gloeosporioides de 79,07\%. Feng \& Zheng (2007) encontraram, utilizando óleo de tomilho, inibição de $62 \%$ do crescimento micelial de Alternaria alternata e consideraram tal resultado promissor para a utilização de óleos de plantas no controle de doenças pós-colheita.

Gomes (2008), investigando a ação dos óleos essenciais de cravo, capim-limão e tomilho sob o IVCM de C. gloeosporioides, encontrou inibição significativa do crescimento do fungo para os três óleos. Sendo que os óleos de tomilho e cravo inibiram completamente o crescimento do fungo na maior concentração utilizada (300 ppm). Tzortzakis \& Economakis (2007), investigando o óleo essencial de capim-limão (Cympopogon citratus) contra os fungos patogênicos Colletotrichum coccodes, Botrytis cinerea, Cladosporium herbarum, Rhizopus stolonifer e Aspergillus niger, in vitro, observaram diminuição significativa do crescimento de todos os fungos.

Provavelmente, o potencial fungitóxico dos óleos essenciais é proveniente do sinergismo entre os seus constituintes (Tripathi \& Dubey, 2004). Dentre os constituintes identificados no óleo essencial de capim-limão (Cympopogon citratus)
(Tzortzakis \& Economakis, 2007) e da Aroeira (Schinus terebinthifolius) o monoterpeno limoneno foi encontrado nos dois óleos, sendo esse monoterpeno um possível princípio ativo contra o crescimento do fungo Colletotrichum gloeosporioides. Entretanto, o mecanismo de ação antifúngica desses óleos ainda não é conhecido (Feng \& Zheng, 2007).

De acordo com Tzortzakis \& Economakis (2007), os compostos voláteis emitidos pelos óleos essenciais têm efeito na superfície de crescimento micelial e na percepção e transdução de sinais envolvidos na mudança de fase de desenvolvimento do fungo (de vegetativa para reprodutiva). Por isso, os óleos também causam impacto no processo de esporulação do fungo.

\section{Controle do fungo Colletotrichum gloeosporioides in vivo \\ O tratamento B foi o que apresentou} menor PMF (Tabela 3), uma vez que o biofilme protetor controla a perda excessiva de água do fruto através da redução da transpiração e da respiração (Oliveira Jr et al., 2005). O tratamento O apresentou PMF bastante elevada, se destacando dos outros tratamentos. Elevados valores de PMF não são desejáveis, já que a desidratação pode interferir nas propriedades físicas, fisiológicas, patológicas, estéticas, nutricionais e econômicas do fruto (Solon et al., 2005).

O tratamento $\mathrm{C}$ apresentou menor firmeza, que pode estar relacionada ao maior amadurecimento destes frutos em virtude desses não terem recebido nenhum tratamento. Já o tratamento $O$ apresentou firmeza maior que os outros tratamentos no oitavo dia após a colheita, o que não é desejável comercialmente, pois frutos excessivamente firmes podem ter a aceitação comercial reduzida, já que não amoleceram devidamente (Jacomino et al., 2002).

De acordo com Xavier (2007), a diminuição dos ácidos orgânicos, ao longo do armazenamento, está relacionada com a utilização destes como

TABELA 3. Valores médios da perda de massa fresca (PMF), firmeza do fruto, acidez titulável (AT), sólidos solúveis (SS) e pH após 8 dias de inoculação do fungo Colletotrichum gloeosporioides em frutos de mamão submetidos a diversos tratamentos de controle do fungo.

\begin{tabular}{lccccc}
\hline & PMF & Firmeza & AT & SS & pH \\
\hline Controle (C) & $40 \mathrm{~b}$ & $1 \mathrm{c}$ & $0,14 \mathrm{a}$ & $13 \mathrm{a}$ & $6,7 \mathrm{a}$ \\
Biofilme (B) & $30 \mathrm{c}$ & $3 \mathrm{~b}$ & $0,09 \mathrm{c}$ & $11,2 \mathrm{~b}$ & $6,5 \mathrm{a}$ \\
Óleo (O) & $70 \mathrm{a}$ & $5,7 \mathrm{a}$ & $0,11 \mathrm{~b}$ & $13,7 \mathrm{a}$ & $6,57 \mathrm{a}$ \\
Fungicida (F) & $42 \mathrm{~b}$ & $1 \mathrm{c}$ & $0,13 \mathrm{a}$ & $13 \mathrm{a}$ & $6,66 \mathrm{a}$ \\
\hline
\end{tabular}

Médias seguidas da mesma letra não diferem estatisticamente, pelo teste de Tukey, a $5 \%$ de probabilidade.

Rev. Bras. PI. Med., Botucatu, v.15, n.1, p.150-157, 2013. 
substrato para respiração. Segundo Oliveira Junior (2005), o decréscimo da AT é explicado pela utilização dos ácidos orgânicos em diversas rotas metabólicas.

Os tratamentos C e F apresentaram os maiores valores de acidez titulável, 0,14 e 0,13, respectivamente. A tendência dos frutos é de perder AT ao longo do amadurecimento, entretanto, pode ocorrer um pequeno aumento da AT com o avanço da maturação (Chitarra \& Chitarra, 2005). $\mathrm{O}$ aumento da AT pode estar relacionado à maior perda de água, uma vez que em virtude desta perda há o efeito da concentração dos ácidos no interior do fruto (Xavier, 2007).

O tratamento $B$ foi o único que não apresentou aumento da AT nos últimos dias e foi também o tratamento que apresentou menor PMF devido ao biofilme. Por isso, relaciona-se à maior quantidade de água dentro desses frutos, em relação aos outros tratamentos, como sendo responsável pela ausência de efeitos de concentração.

Em relação aos diferentes tratamentos, o C apresentou valores de AT maiores. Esta maior quantidade de ácidos orgânicos pode estar relacionada ao maior amadurecimento dos frutos controle, já que eles também apresentaram maior perda de firmeza. Tanto a característica de maior AT quanto de menor firmeza estão relacionados à maior ação da enzima pectinametilesterase e, consequentemente maior amadurecimento (Xavier, 2007).

O tratamento $\mathrm{B}$ apresentou o menor valor de SS $\left(11,2^{\circ}\right.$ Brix $)$, tal fato pode estar relacionado ao amadurecimento do fruto, já que, a degradação de polissacarídeos de reserva e da parede celular e a perda de água é que resultam em maior concentração dos SS no fruto (Xavier, 2007).

Todos os tratamentos se apresentaram semelhantes em relação ao $\mathrm{pH}$. Os valores do $\mathrm{pH}$ estão de acordo com Chitarra \& Chitarra (2005), que afirmaram que as frutas têm a acidez diminuída ao longo do amadurecimento e que o mamão mais maduro possui maior $\mathrm{pH}$.

$\mathrm{O}$ tratamento $\mathrm{O}$ diferiu, significativamente, dos outros tratamentos, apresentando maior $\mathrm{pH}$. É possível que este resultado esteja relacionado ao stress causado pelo óleo no fruto. Carvalho \& Lima (1998) também relacionaram ao stress sofrido por um tratamento, a diferença de $\mathrm{pH}$ apresentada; em relação aos demais tratamentos.

Após oito dias da inoculação, foi realizada a determinação da incidência (número de frutos infetados em cada tratamento) e da severidade da doença (superfície externa do fruto ocupada por lesão em \%). De acordo com os resultados referentes ao controle de C.gloesporioides (Tabela 4 ), verificou-se que os tratamentos com óleo e
TABELA 4. Valores médios da incidência (I) e da severidade (S) do ataque do fungo Colletotrichum gloeosporioides após 8 dias de inoculação em frutos de mamão submetidos a diversos tratamentos de controle do fungo.

\begin{tabular}{lcc}
\hline & Incidência (I) & Severidade (S) \\
\hline Controle (C) & 100 & 37 \\
Biofilme (B) & 100 & 31 \\
Óleo (O) & 0 & 0 \\
Fungicida (F) & 0 & 0 \\
\hline
\end{tabular}

$\mathrm{I}=$ (№ de frutos infectados/ № Total de frutos) $\times 100 ; \mathrm{S}=$ (Diâmetro médio da lesão/Tamanho do fruto) x 100

fungicida reduziram a incidência e a severidade da doença, em comparação com o controle. O melhor desempenho para o controle da doença foi obtido com o óleo a $1,0 \%$, semelhante ao controle obtido pelo fungicida benomil.

Pelo exposto, evidencia-se que o óleo essencial de S. terebinthifolius pode vir a ser usado como alternativa ao controle da antracnoseintegrando-se às técnicas de pós-colheita. Essas técnicas, que consistem no emprego de extratos vegetais, aminoácidos, microrganismos e agora óleos essenciais, enquadram-se como estratégias de controle biológico de patógenos de plantas (Franco \& Bettiol, 2000).

Com os resultados obtidos neste trabalho, pode-se observar que o óleo de S. terebinthifolius, além de ser um produto biológico natural, apresenta potencial de uso para o controle da podridão de frutos de mamão causada por $C$. gloesoiriodes em pós-colheita, com a vantagem de minimizar o uso dos fungicidas convencionais, de preservar o meio ambiente e oferecer proteção à saúde do consumidor. Neste contexto, o óleo deve ser testado em condições comerciais visando o controle da antracnose em pós-colheita em frutos de mamoeiro.

A análise antifúngica revelou a presença de sintomas de antracnose ao redor do local de inoculação apenas nos tratamentos B e C. Verificouse, por isso, que $\mathrm{O}$ e $\mathrm{F}$ foram eficientes contra $\mathrm{O}$ fungo $C$. gloeosporioides.

Visualmente, os frutos tratados com óleo de S. terebinthifolius, na concentração utilizada, apresentaram injúrias, as quais aumentaram ao longo do tempo. As injúrias relacionam-se ao efeito de fitotoxidade desse óleo essencial em frutos do mamoeiro, tornando-os impróprios para o comércio. Plotto et al., (2003) também encontraram fitotoxidade em frutos de tomate quando estes foram tratados com emulsão de nardo.

O mamoeiro é uma planta considerada muito sensível à fitotoxidade, sendo que o grau

Rev. Bras. PI. Med., Botucatu, v.15, n.1, p.150-157, 2013. 
deste efeito é variável em relação aos produtos e às formulações do mesmo produto utilizado no controle de pragas e doenças (Vieira et al., 2003). Desta forma, é provável que o óleo essencial de S. terebinthifolius possa ser utilizado para inibir o crescimento do fungo $C$. gloeosporioides durante a vida de prateleira de outras frutas que também são atacadas por este fungo, mas que não sejam muito sensíveis à fitotoxidade, como o fruto do mamoeiro.

Este estudo possibilita inferir que o óleo essencial extraído do fruto de $S$. terebinthifolius apresentou atividade fungitóxica contra o fungo $C$. gloeosporioides in vitro. A inibição do crescimento do fungo foi diretamente proporcional à concentração do óleo e a maior concentração utilizada $(0,50 \%)$ apresentou inibição de $79,07 \%$.

O tratamento com óleo essencial in vivo, em mamão, se revelou eficiente contra o fungo $C$. gloeosporioides durante o período pós-colheita avaliado. Todavia, o mesmo não é indicado para o comércio em virtude da elevada perda de massa fresca e maior firmeza, e de características visuais que demonstraram sintomas de fitotoxidade. Sugere-se pesquisas que explorem a viabilidade da utilização do óleo de $S$. terebinthifolius para controle o fungo $C$. gloeosporioides em outros frutos que não sejam muito sensíveis à fitotoxidade.

\section{AGRADECIMENTO}

Agradecemos à Empresa Caliman S.A. pelos frutos cedidos, ao Instituto Capixaba de Pesquisa, Assistência Técnica e Extensão Rural pelo fornecimento do fungo Colletotrichum gloeosporioides ${ }_{2}$ e à Fundação de Apoio à Ciência e Tecnologia do Espírito Santo.

\section{REFERÊNCIA}

ADAMS, R. P.; Identification of Essential Oil Components by Gas Cromatography I Mass Spectroscopy, Allured Publishing Corporation: Carol Stream, 2001.

AOAC. Association of official_analytical chemists. Official methods of analysis of the Association of Official Analytical Chemists. 12. ed. Washington: AOAC, 1992. 1115p.

BARBOSA, L. C. A. et al. Seasonal variation in the composition of volatile oils from Schinus terebintifolius RADDI. Química Nova, v. 30, n 8, p. 1959 - 1965, 2007. BRAGA, F.G. et al. Antileishmanial and antifungal activity of plants used in traditional medicine in Brazil. Journal of Ethnopharmacology, v.111, p.396-402, 2007.

BASTOS, C.N. Efeito do óleo de Piper aduncum sobre Crinipelis perniciosa e outros fungos fitopatogênicos. Fitopatologia Brasileira, v.22, n.3, p.44-3, 1997.

CARVALHO, A.V.; DAIUTO, A.R.; LIMA, L.C.O. Qualidade de mamão (Carica papaya) minimamente processado e armazenado em condições refrigeradas. Revista da
Universidade de Alfenas, v.4, p.137-40, 1998. CHITARRA, M.I.F.; CHITARRA, A.B. Pós-colheita de frutos e hortaliças: fisiologia e manuseio. 2.ed. LavrasMG:ESAL/FAEPE, 2005. 785p.

COLE, E.R. Estudo fitoquímico do óleo essencial dos frutos da aroeira (Schinus terebinthifolius Raddi) e sua eficácia no combate ao dengue. 2008. 66p. Dissertação (Mestrado em Química) - Universidade Federal do Espírito Santo, Vitória.

DAVID, E.F.S. et al. Rendimento e composição do óleo essencial de Mentha piperita L., cultivada em solução nutritiva com diferentes níveis de fósforo. Revista Brasileira de Plantas Medicinais, v.8, n.4, p.183-8, 2006. FENG, W. et al. Combination of cassia oil with magnesium sulphate for control of postharvest storage rots of cherry tomatoes. Crop Protection, v.27, p.112-5, 2008.

FENG, W.; ZHENG, X. Essential oils to control Alternaria alternata in vitro and in vivo. Food Control, v.18, p.112630, 2007.

FRANCO, D.A.S.; BETTIOL, W. Controle do bolor verde em pós-colheita de citros com produtos alternativos. In: AMBROSIANO, E. (Coord.) Agricultura ecológica. Guaíba: Agropecuária. 1999, p.121-30.

GOMES, L.I.S. Métodos de inoculação de Colletotrichum gloeosporioides e efeitos de óleos essenciais no controle da antracnose em frutos de mamoeiro. 2008. 54p. Dissertação (Mestrado em Agronomia) - Universidade Federal de Lavras, Lavras. IBRAHIM, M. A. et al. Insecticidal, repellent, antimicrobial activity and phytotoxicity of essential oils: with special reference to limonene and its suitability for control of insect pests Agricultural and Food Science IN FINLAND, v. 10, p.243-259, 2001.

JACOMINO, A.P. et al. Amadurecimento e senescência de mamão com 1-metilciclopropeno. Scientia Agricola, v.59, n.2, p.303-8, 2002.

JOHANN, S. et al. Antifungal properties of plants used in brazilian traditional medicine against clinically relevant fungal pathogens. Brazilian Journal of Microbiology, v.38, p.632-7, 2007.

LENZI, M.; ORTH, A.I. Caracterização funcional do sistema reprodutivo da aroeira vermelha (Schinus terebinthifolius Raddi) em Florianópolis-SC, Brasil. Revista Brasileira de Fruticultura, v.26, n.2, p.198-201, 2004.

LISBOA-NETO, J. et al. Avaliação do efeito cicatrizante da Aroeira (Schinus terebinthifolius) e do mastruço (Chenopodium ambrosioides) em feridas de extração dental em ratos: estudo histológico. Revista da Associação Brasileira de Odontologia, v.6, p.173-5, 1998.

OLIVEIRA JÚNIOR, L.F.G.; COELHO, E.M.; COELHO, F.C. Utilização de atmosfera modificada na conservação do mamão (Carica papaya L.) 'Golden' sob refrigeração. Revista Brasileira de Armazenamento, v.30, n.1, p.73-7, 2005.

PAIVA, A.M.S.; ALOUFA, M.A.I. Estabelecimento in vitro de aroeira da praia (Schinus terebinthifolius Raddi) em diferentes concentrações de 6-benzilaminopurina (BAP). Revista Brasileira de Plantas Medicinais, v.11, n.3, p.300-4, 2009.

PLOTTO, A.; ROBERTS, D.D.; ROBERTS, R.G. Evaluation of plant essential oils as natural postharvest disease control of tomato (Lycopersicon esculentum). Acta

Rev. Bras. PI. Med., Botucatu, v.15, n.1, p.150-157, 2013. 
Horticulturae, v.628, p.737"45, 2003.

REGNIER, T. et al. Fungitoxicity of Lippia scaberrima essential oil and selected terpenoid components on two mango postharvest spoilage pathogens. Postharvest Biology and Technology, v.48, p.254-8, 2008.

SHARMA, N.; TRIPATHI, A. Integrated management of postharvest Fusarium rot of gladiolus corms using hot water, UV-C and Hyptis suaveolens (L.) Poit. essential oil. Postharvest Biology and Technology, v.47, p.24654, 2008.

SANTOS, M. R. A. et al. Atividade inseticida do óleo essencial de Schinus terebinthifolius Raddi sobre Acanthoscelides obtectus Say e Zabrotes subfasciatus Boheman Boletim de Pesquisa e Desenvolvimento Embrapa, v. 48, 13p 2007.

SILVA, F.; CASALI, V.W.D. Plantas medicinais e aromáticas: pós-colheita e óleos essenciais. Viçosa: UFV, 2000. 135p.

SOLON, K.N. et al. Conservação pós-colheita do mamão formosa produzido no Vale do Assu sob atmosfera modificada. Revista Caatinga, v.18, n.2, p.105-11, 2005. TRIPATHI, P.; DUBEY, N.K. Exploitation of natural products as an alternative strategy to control postharvest fungal rotting of fruit and vegetables. Review. Postharvest
Biology and Technology, v.32, p.235-45, 2004. TZORTZAKIS, N.G.; ECONOMAKIS, C.D. Antifungal activity of lemongrass (Cympopogon citratus L.) essential oil against key postharvest pathogens. Innovative Food Science and Emerging Technologies, v.8, p.253-8, 2007.

VIEIRA, A.; RUGGIERO, C.; MARIN, S.L.D. Fitotoxidade de fungicidas, acaricidas e inseticidas sobre o mamoeiro (Carica papaya L.) cultivar Sunrise Solo Improved Line 72/12. Revista Brasileira de Fruticultura, v. 25, n.1, p.175-8, 2003.

XAVIER, V.L.S.M. Processamento mínimo de mamão e abacaxi: respostas fisiológicas, bioquímicas e microbiológicas. 2007. 86p. Dissertação (Mestrado em Biologia Vegatal) - Universidade Federal do Espírito Santo, Vitória.

WATERMAN, P.G. The chemistry of volatile oils. In: HAY, R.K.M.; WATERMAN, P.G. (Eds.). Volatile oil crops: their biology, biochemistry and production. Harlow: Longman Scientific, Technical, 1993. 185p.

WASICKY, R.; AKISUE, G. Um aparelho aperfeiçoado para a extração de óleos essenciais. Revista da Faculdade de Farmácia Bioquímica da Universidade de São Paulo, v.7, p.339-405, 1969. 